\title{
THE MODULATION OF HAEMOLYTIC ACTIVITY OF NON-IONIC SURFACTANTS BY OIL-IN-WATER MICROEMULSIONS AS VEHICLES FOR PARENTERAL DRUG DELIVERY
}

\author{
M.T. Bayor, ${ }^{1,2}$ and M.J. Lawrence ${ }^{2}$ \\ ${ }^{1}$ Faculty of Pharmacy, Kwame Nkrumah University of Science \\ and Technology, Kumasi, Ghana. \\ ${ }^{2}$ Department of Pharmacy, \\ King's College London, SE1 8WA, UK
}

\begin{abstract}
Microemulsions are thermodynamically stable, clear, transparent fluid dispersions of oil, water, and surfactant, but may include a cosurfactant typically a short chain alcohol. The unique properties of microemulsions make them suitable candidates as vehicles for improving parenteral drug delivery. In the present study, we report of our investigations into the ability of some commercial non-ionic surfactants to produce o/w microemulsions with different oils and water or phosphate buffered saline (PBS), their physicochemical properties and modulation of haemolytic activity on human erythrocytes. The compositions over which clear o/w microemulsion systems formed and their areas of existence were dependent on the structure of the non-ionic surfactant and the oil incorporated. The clear o/w microemulsion systems remained clear and stable even on dilution with water or PBS. The haemolytic activities of the micellar solutions of the non-ionic surfactants were dependent on the nature and concentration of the surfactant. Generally, the clear o/w microemulsion systems were greatly less haemolytic than their corresponding micellar solutions at equivalent concentrations of surfactant. This indicated a high modulation of the haemolytic activity of the surfactants by the microemulsion formulations. The modulation of haemolytic activity was greatest with microemulsions formulated with the highest possible oil/surfactant ratios. The use of relatively longer triglycerides (oils) greatly enhanced the modulation activity of the resultant microemulsions. Our findings signified a high level of safety associated with the o/w microemulsions and lent a good support and credence to the high potential of microemulsions as suitable and safe vehicles for parenteral drug administration.
\end{abstract}

Keywords: Oil-in-water (o/w) microemulsions, micellar solutions, non-ionic surfactants, modulation, haemolytic activity, drug delivery, parenteral administration 


\section{INTRODUCTION}

The poor aqueous solubility of many drugs, low stability due to enzymatic hydrolysis and other degradation processes, poor absorption, low bioavailability profiles as well as the need for sustained release and targeted delivery, have all raised attention in pharmaceutical research and application and have led to the design, development and formulation of new dosage forms. In recent years emphasis have been laid on the development of lipid-based systems especially microemulsions for improved drug solubilisation, protection, stability and delivery as well as absorption enhancement (Fubini et al., 1989; Malcolmson and Lawrence, 1993).

Our interest is based on exploiting the many advantages of microemulsions over conventional formulations as potential candidates for improved drug delivery. We envisaged that, the ease and simplicity of preparation of microemulsions can aid their large scale industrial production. Their thermodynamic stability even on addition of medicaments, their relative tolerance to changes in temperature and mechanical vibrations in transport and storage indicates that the properties of the formulation would not depend upon processing and the product would not phase separate. Due to their small particle size, they can be sterilised by filtration and can easily pass through blood vessels. Their transparency offers an ease of inspection for undissolved and undeserved particles, bacteria and other contaminants.

As such o/w microemulsions can provide a water-continuous dosage form which can be used to deliver water-insoluble drugs, while w/o microemulsions can provide a means of incorporating, protecting and increasing the bioavailability of some water soluble molecules such as peptides, and could therefore avoid the undesirable effects of parenteral administration of suspensions, or the need to add cosolvents or to chemically modify the drug molecule (Bhargava et al., 1987).

As surfactant systems the haemolytic and other membrane effects of these microemulsions need to be thoroughly investigated in order to determine their suitability for parenteral drug delivery, thence the current study for which we now report.

\section{MATERIALS AND METHODS}

\section{Materials}

The surfactants used in the study were; Polyoxyethylene 10 oleyl ether $\left[\left(\mathrm{C}_{18-1} \mathrm{E}_{10}\right)\right.$ (i.e. $\left.\mathrm{C}_{9} \mathrm{H}_{18}=\mathrm{C}_{9} \mathrm{H}_{17}\left(\mathrm{OCH}_{2} \mathrm{CH}_{2}\right)_{10} \mathrm{OH}\right) \quad($ Brij 96/97)] (SIGMA, UK Ltd); Polyoxyethylene 10 lauryl ether $\left[\left(\mathrm{C}_{12} \mathrm{E}_{10}\right)\right.$ (i.e. $\left.\left.\mathrm{C}_{12} \mathrm{H}_{25}\left(\mathrm{OCH}_{2} \mathrm{CH}_{2}\right)_{10} \mathrm{OH}\right)\right]$ (SIGMA, UK Ltd); N'N'-Dimethyldodecylamine-N-oxide $\left[\left(\mathrm{C}_{12} \mathrm{~N}-\mathrm{O}\right)\right.$ (i.e. $\mathrm{CH}_{3}\left(\mathrm{CH}_{2}\right)_{11} \mathrm{~N}$ $\left.\left(\mathrm{CH}_{3}\right)_{2} \mathrm{O}\right)$ ] (Fluka, Switzerland) and Epikuron 200 (Lecithin) (Lucas Meyer, Hamburg). The oils (acid esters) were; Ethyl butyrate $\left[\mathrm{CH}_{3}\left(\mathrm{CH}_{2}\right)\right.$ $\left.{ }_{2} \mathrm{COOC}_{2} \mathrm{H}_{5}\right]$; Ethyl caprylate $\left[\mathrm{CH}_{3}\left(\mathrm{CH}_{2}\right)\right.$ $\left.{ }_{6} \mathrm{COOC}_{2} \mathrm{H}_{5}\right]$ and Ethyl oleate $\left[\mathrm{CH}_{3}\left(\mathrm{CH}_{2}\right)\right.$ ${ }_{7} \mathrm{CH}=\mathrm{CH}\left(\mathrm{CH}_{2}\right)_{7} \mathrm{COOC}_{2} \mathrm{H}_{5}$ ] all from SIGMA, UK Ltd.

The other reagents included; Sodium Chloride $(\mathrm{NaCl})$, Potassium Chloride $(\mathrm{KCl})$, Disodium hydrogen orthophosphate $\left(\mathrm{Na}_{2} \mathrm{HPO}_{4}\right)$, Potassium dihydrogen phosphate $\left(\mathrm{KH}_{2} \mathrm{PO}_{4}\right)$, Calcium Chloride dihydrate $\left(\mathrm{CaCl}_{2} .2 \mathrm{H}_{2} \mathrm{O}\right)$, Magnesium Chloride hexahydrate $\left(\mathrm{MgCl}_{2} \cdot 6 \mathrm{H}_{2} \mathrm{O}\right)$ all from $\mathrm{BDH}$ Ltd, Phosphate Buffered Saline (PBS) (Tablets) from OXOID, UK Ltd., Drabkin's Reagent, SIGMA, UK Ltd. and Polyoxyethylene 23 lauryl ether (Brij.35) $(30 \% \mathrm{w} / \mathrm{v})$, SIGMA, UK Ltd. Other materials used included fresh human blood (Groups A and AB, $\mathrm{Rh}^{-\mathrm{ve}}$ ) obtained from the Regional Transfusion Centre, Tooting Broadway, London.

\section{Methods \\ Phosphate Buffered Saline (PBS) pH 7.4}

Dulbecco's A - Phosphate Buffered Saline consisting of; $\mathrm{NaCl}(10 \mathrm{gm} / \mathrm{L}), \mathrm{KCl}(0.25 \mathrm{gm} / \mathrm{L})$, $\mathrm{NaHPO}_{4}(1.44 \mathrm{gm} / \mathrm{L}), \mathrm{KH}_{2} \mathrm{PO}_{4}(0.25 \mathrm{gm} / \mathrm{L})$ in water and with a pH 7.4 was used throughout. To obtain a Complete Phosphate Buffered Saline, $20 \mathrm{mleach}$ of $\mathrm{CaCl}_{2} .2 \mathrm{H}_{2} \mathrm{O} \quad(1 \mathrm{gm} / \mathrm{L})$ and $\mathrm{MgCl}_{2} \cdot 6 \mathrm{H}_{2} \mathrm{O}(1 \mathrm{gm} / \mathrm{L})$, were added to $160 \mathrm{ml}$ of the Dulbecco's A Phosphate Buffered Saline.

44 Journal of Science and Technology, Volume 27 no. 2, August, 2007 


\section{Micellar Solutions}

The surfactants were dissolved in water or phosphate buffered saline (PBS) at a maximum concentration of $1 \% \mathrm{w} / \mathrm{w}$. They were usually heated to $70^{\circ} \mathrm{C}$ to promote solubilisation and allowed to cool to room temperature with constant magnetic stirring. The resulting micellar solutions were then diluted with water or the PBS as required.

\section{Formation of Microemulsions}

The appropriate proportions of the various components (surfactant, oil and water or PBS) were accurately weighed into a small conical flask, a magnetic flea introduced and the top of the flask covered with foil or stopper and the contents heated with constant stirring at $70^{\circ} \mathrm{C}$ in a water bath for about 5 to 10 minutes, transferred immediately onto a stirrer and allowed to cool to room temperature $\left(21^{\circ} \mathrm{C}\right)$ with constant magnetic stirring. The production of an optically clear nonbirefringent fluid system, stable for a month was taken as indicative of microemulsion formation.

\section{Phase Diagrams}

The area of existence of the clear $\mathrm{o} / \mathrm{w}$ microemulsions were determined by preparation of a large number of samples containing different proportions of non-ionic surfactants, oil and water or PBS. Phase diagrams were then drawn by plotting the results on triangular co-ordinates. A line joining the outermost clear points indicated clearly the area of existence of the microemulsion system.

\section{Effects of Electrolytes on the Formation and Stability of the Microemulsions}

The effects of ions such as $\mathrm{Na}^{+}, \mathrm{K}^{+}, \mathrm{Cl}^{-}$and $\mathrm{HP}^{-}$, on the formation and area of existence of the $\mathrm{o} / \mathrm{w}$ microemulsions were investigated by replacement of the water with Dulbecco's A phosphate buffered saline $\mathrm{pH} 7.4$, in the preparation of the microemulsions.

Dilution of the Micellar Solutions and Microemulsions

The micellar solutions and the o/w microemul- sion systems were diluted with the aqueous phase (distilled water or phosphate buffered saline $\mathrm{pH}$ 7.4) to obtain solutions of various concentrations of surfactant. The micellar solutions were diluted serially from initial concentrations of $1 \% \mathrm{w} / \mathrm{w}$ to as low as $0.01 \% \mathrm{w} / \mathrm{v}$ of surfactant. The microemulsions were however diluted from various concentrations such as; $15 \%, 20 \%, 25 \%$ $\mathrm{w} / \mathrm{w}$, etc. to $1 \% \mathrm{w} / \mathrm{v}$ surfactant and further down to $0.01 \% \mathrm{w} / \mathrm{v}$ surfactant.

\section{Preparation of Drabkin's Reagent Solution}

Each pre-weighed vial of Drabkin's reagent (1.25gm) was dissolved in, and made up to 1 litre with distilled water. A $0.5 \mathrm{~m} 1$ of $30 \% \mathrm{w} / \mathrm{v}$ Brij. 35 , was then added and mixed thoroughly. The prepared solutions were stored in amber coloured bottles in a dark cupboard until required for use.

\section{Preparation of Test Samples}

The micellar solutions and microemulsions used in the haemolytic studies were prepared as detailed in the earlier sections. However, only Dulbecco' A, phosphate buffered saline (PBS) $\mathrm{pH} 7.4$, was used as the aqueous phase. Both micelles and microemulsions were serially diluted with the PBS, to obtain test samples with varying concentrations ranging from $0.01 \% \mathrm{w} / \mathrm{V}$ to $1.0 \% \mathrm{w} / \mathrm{v}$ of surfactant, although with the micellar solutions, sample concentrations ranging from $0.01 \% \mathrm{w} / \mathrm{v}$ to $0.1 \% \mathrm{w} / \mathrm{v}$ surfactant were mostly used.

\section{Determination of Haemolytic Activity}

The blood was obtained already heparinised. About $3 \mathrm{~g}$ samples of the blood were weighed into pre-weighed centrifuge tubes and centrifuged at 3300rpm for 10 minutes. The plasma and buffy coat were removed and discarded. The erythrocytes were then washed three times with about five times their volume of phosphate buffered saline (PBS) $\mathrm{pH} 7.4$, each time removing the buffy coat after spinning for 10 minutes at $3300 \mathrm{rpm}$. The erythrocytes were resuspended in the PBS solution to give a $12 \%$ haematocrit. 
Samples of $0.2 \mathrm{ml}$ each of the erythrocyte suspension were carefully added to $0.2 \mathrm{~m} 1$ portions of appropriate tests solutions (PBS, micellar or microemulsion), in microcentrifuge (Eppendorf) tubes, and incubated in a shaking water bath at $20^{\circ} \mathrm{C}$ for 30 minutes. The samples were then spun in a microcentrifuge for 15 seconds and $0.2 \mathrm{~m} 1$ samples of the supernatant of each tube transferred into $3 \mathrm{ml}$ of Drabkin's reagent solution. These were then allowed to stand for 15 minutes and the absorbance of the samples measured at 540nm on a UV/VIS Spectrophotometer (PERKIN-ELMER Lambda 5 UV/VIS Spectrophotometer).

The test samples run in PBS, served as controls. Centrifuged control samples were assayed to provide values of possible spontaneous haemolysis, while, the content of uncentrifuged controls were thoroughly mixed after incubation and $0.2 \mathrm{ml}$ samples transferred into $3 \mathrm{ml}$ Drabkin's reagent and assayed as described to obtain values for complete or $100 \%$ haemolysis.

The absorbance of the test samples were then expressed as a percentage of the $100 \%$ haemolytic value. From the results the concentration of surfactant that produced $50 \%$ haemolysis $\left(\mathrm{C}_{50}\right)$ in each system were determined by linear regression analysis. All the samples were prepared and assayed in triplicate, and the entire experimental procedure repeated at least twice for each system examined.

\section{RESULTS AND DISCUSSION}

\section{Characterisation of the Microemulsions}

The investigations revealed variations in the ability of the commercial non-ionic surfactants $\left(\mathrm{C}_{18}\right.$ ${ }_{1} \mathrm{E}_{10}, \mathrm{C}_{12} \mathrm{E}_{10}$ and $\mathrm{C}_{12} \mathrm{~N}-\mathrm{O}$ ) and the oils (ethyl butyrate, ethyl caprylate and ethyl oleate) to form oil-in-water $(\mathrm{o} / \mathrm{w})$ microemulsions with water or phosphate buffered saline (PBS). For each formulation the production of an optically clear, transparent and non-birefringent fluid system stable for a month was taken as indicative of microemulsion formation. Formulations that de- viated from these were either turbid, cloudy or formed a gel.

All the oils were able to form stable and dilutable $\mathrm{o} / \mathrm{w}$ microemulsions with each of the surfactants and water or PBS. The use of PBS, had no effect on the formation, stability and area of the clear o/ $\mathrm{w}$ microemulsions produced by these non-ionic surfactants, which indicated that these microemulsions would not be adversely affected by reasonable physiological changes (Aveyard et al., 1981; Holtzschere and Candau, 1988). Also all the diluted microemulsions and micellar systems used in these investigations were clear and stable at room temperature for at least a month; hence the microemulsions were described as "dilutable" (Langevin, 1991). However, the compositions that formed stable microemulsions were dependent on the type of oil and surfactant used.

Generally, the partial phase diagrams showed clearly a decrease in the maximum oil incorporated and the area of existence of the o/w microemulsions as the oil was changed from ethyl butyrate to ethyl caprylate and to ethyl oleate for each particular surfactant (Fig.1a). With the $\mathrm{C}_{12} \mathrm{~N}-\mathrm{O}$ surfactant systems, the maximum oils incorporated were $24 \% \mathrm{w} / \mathrm{w}$ ethyl butyrate, $16 \%$ w/w ethyl caprylate and $6 \% \mathrm{w} / \mathrm{w}$ ethyl oleate (Table 1). These indicated that, larger amounts of shorter alkyl chain oils were incorporated than longer alkyl chain oils (Malcolmson, 1992; Attwood, 1993).

Amongst the surfactants used, there was a general increase in the amount of oil incorporated and the area of microemulsion existence in the order; $\mathrm{C}_{18-1} \mathrm{E}_{10}<\mathrm{C}_{12} \mathrm{E}_{10}<\mathrm{C}_{12} \mathrm{~N}-\mathrm{O}$, for each oil employed (Fig.1b).

The amount of ethyl butyrate incorporated increased from $8 \% \mathrm{w} / \mathrm{w}$ to $15 \% \mathrm{w} / \mathrm{w}$ and $24 \% \mathrm{w} / \mathrm{w}$ for $\mathrm{C}_{18-1} \mathrm{E}_{10}(5-30 \% \mathrm{w} / \mathrm{w}), \mathrm{C}_{12} \mathrm{E}_{10} \quad(3-34 \% \mathrm{w} / \mathrm{w})$ and $\mathrm{C}_{12} \mathrm{~N}-\mathrm{O}(2-38 \% \mathrm{w} / \mathrm{w})$ respectively, with a corresponding increase in areas of existence (Table 1).

46 Journal of Science and Technology, Volume 27 no. 2, August, 2007 

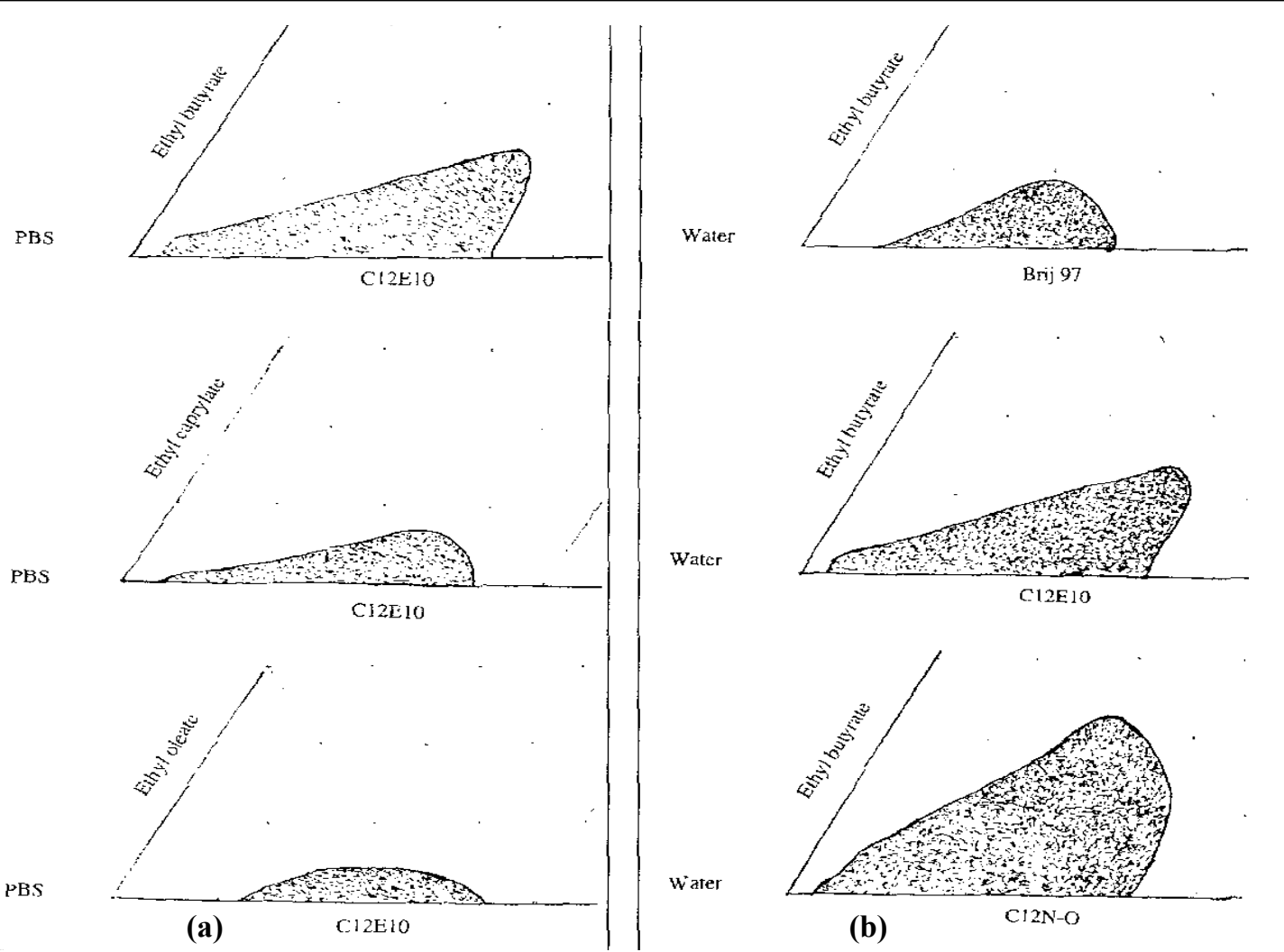

(b)

Fig. 1: (a) Areas of existence of C12E10/EB, EC \& EO/PBS microemulsions

(b) Areas of existence of EB/Brij96, C12E10 \& C12N-O/Water microemulsions

Considering the three non-ionic surfactants, $\mathrm{C}_{18}$ ${ }_{1} \mathrm{E}_{10}$ and $\mathrm{C}_{12} \mathrm{E}_{10}$ have similar polyoxyethylene (POE) chain lengths, but $\mathrm{C}_{18-1} \mathrm{E}_{10}$ has a longer hydrocarbon (alkyl) chain, than $\mathrm{C}_{12} \mathrm{E}_{10}$ and $\mathrm{C}_{12} \mathrm{~N}$ $\mathrm{O}$. The results therefore indicated that an increase in the alkyl chain length of the surfactant decreased the amount of oil incorporated and the area of existence of the $\mathrm{o} / \mathrm{w}$ microemulsions. Also, the $\mathrm{N}$-oxide of $\mathrm{C}_{12} \mathrm{~N}-\mathrm{O}$ is a larger hydrophilic head group (Lawrence and Devinsky, 1988) than the POE chain of $\mathrm{C}_{12} \mathrm{E}_{10}$, and that appears to support its $\left(\mathrm{C}_{12} \mathrm{~N}-\mathrm{O}\right)$ ability to incorporate more oil.

\section{Haemolytic Studies}

The studies showed clearly the haemolytic activity of micellar solutions of the non-ionic surfac- tants (Brij 96, $\mathrm{C}_{12} \mathrm{E}_{10}, \mathrm{C}_{12} \mathrm{~N}-\mathrm{O}$ and a mixture of Epikuron 200 and $\mathrm{C}_{12} \mathrm{~N}-\mathrm{O}$ in a ratio of $1: 2 \mathrm{w} / \mathrm{w}$ ) as well as the effects of microemulsions containing these surfactants and the oils (ethyl oleate and ethyl butyrate), in phosphate buffered saline (PBS), pH 7 on human erythrocytes. The micellar solutions of all the non-ionic surfactants employed in these studies exhibited concentration dependent haemolytic activity on the human erythrocytes which decreased in the order; Brij $96>\mathrm{C}_{12} \mathrm{E}_{10}>\mathrm{C}_{12} \mathrm{~N}-\mathrm{O}>$ Epikuron 200: $\mathrm{C}_{12} \mathrm{~N}-\mathrm{O}$ (Fig. 2), with the surfactant concentrations producing $50 \%$ haemolysis $\left(\mathrm{C}_{50}\right)$ as; $0.044,0.052$, 0.064 , and $0.098 \% \mathrm{w} / \mathrm{v}$ respectively (Table 2 ). The results showed that, the haemolytic effects of these systems were also related to the type and 
The modulation of haemolytic activity of non-ionic surfactants ...

Table 1: The areas of existence of the $\mathrm{o} / \mathrm{w}$ microemulsions, indicating the amounts of SAA's and maximum oils incorporated

\begin{tabular}{ccc}
\hline Surfactants \& Oils & $\begin{array}{l}\text { Area of o/w microe- } \\
\text { mulsion existence } \\
\text { (\%w/w SAA) in Wa- } \\
\text { ter/PBS }\end{array}$ & $\begin{array}{l}\text { Maximum oil incor- } \\
\text { porated/Surfactant } \\
\text { concentration } \mathbf{\%} \text { w/ } \\
\text { w) in Water/PBS }\end{array}$ \\
\hline $\mathrm{C}_{18-1} \mathrm{E}_{10}$ & $\mathbf{5 - 3 0}$ & \\
Ethyl butyrate & $10-28$ & $8 / 20$ \\
Ethyl caprylate & $5-27$ & $7 / 25$ \\
Ethyl oleate & $12-30$ & $5 / 25$ \\
$\mathrm{C}_{12} \mathrm{E}_{10}$ & $\mathbf{3}-\mathbf{3 4}$ & \\
Ethyl butyrate & $3-33$ & $15 / 30$ \\
Ethyl caprylate & $3-33$ & $8 / 25$ \\
Ethyl oleate & $13-34$ & $4 / 25$ \\
$\mathrm{C}_{12} \mathrm{~N}-\mathrm{O}$ & $\mathbf{2}-\mathbf{3 8}$ & \\
Ethyl butyrate & $3-34$ & $24 / 20$ \\
Ethyl caprylate & $2-34$ & $16 / 25$ \\
Ethyl oleate & $3-38$ & $6 / 20$ \\
\hline
\end{tabular}

nature of the non-ionic surfactant (Lawrence and Devinsky, 1988; Martin et al., 1992).

From these results it seemed clear that the alkyl chain length or hydrophobicity of the amphiphile played an important role in their interactions with biomembranes (Coleman and Holdsworth, 1975); with the more hydrophobic being more damaging morphologically (Coleman et al., 1980; Ziv et al., 1983). Osborne et al (1991) in their studies concluded that, the surfactant concentration required to produce a given membrane effect was dependent upon the surfactant structure rather than on the cell investigated.

Like the micellar solutions, the microemulsions also produced some haemolytic activity on the human erythrocytes. However, the microemulsions were generally much less haemolytic compared with their corresponding micellar solutions at similar concentrations of surfactant. This indicated a modulation of the haemolytic activity of the surfactants by the microemulsion formulations.

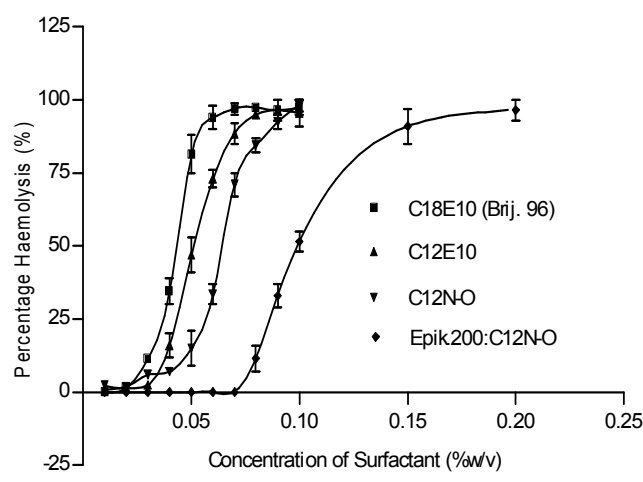

Fig. 2: The haemolytic effects of micelles of the non-ionic surfactants on human erythrocytes

Figure 3 shows the haemolytic effects of Brij 96 micelles and its microernulsions at ratios of $20 / 4$ and 20/6 with ethyl oleate. The microemulsions significantly reduced the haemolytic effects of the surfactant. The 20/6 microemulsion, regis-

48 Journal of Science and Technology, Volume 27 no. 2, August, 2007 


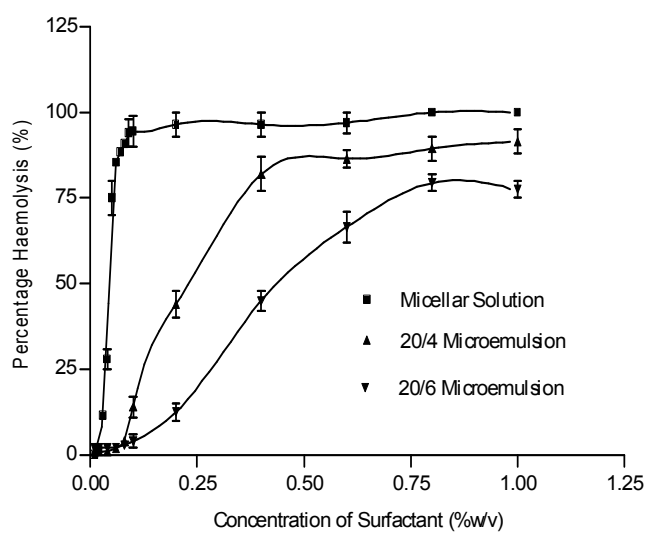

Fig. 3: The haemolytic effects of C18-1E10 micelles and its ethyl oleate/PBS microemulsions on human erythrocytes

tered a $\mathrm{C}_{50}$ value of $0.42 \% \mathrm{w} / \mathrm{v}$ as against $0.044 \%$ $\mathrm{w} / \mathrm{v}$ for the micellar solution (Table 2) representing close to a $900 \%$ modulation of haemolytic activity.

Similarly, Fig. 4 showed the haemolytic effects of the micellar solution of a 1:2 w/w mixture of Epikuron 200 with $\mathrm{C}_{12} \mathrm{~N}-\mathrm{O}$ and its $20 / 6 \% \mathrm{w} / \mathrm{w}$ microemulsion with ethyl oleate in PBS. The microemulsions showed a significant reduction of haemolytic effects $\left(\mathrm{C}_{50}=0.160-0.320 \% \mathrm{w} / \mathrm{v}\right)$ compared to the micellar solutions $\left(\mathrm{C}_{50}=\right.$ $0.098 \% \mathrm{w} / \mathrm{v}$ ) with up to over $200 \%$ modulation of haemolytic activity.

The modulation of haemolytic activity of the surfactant by formulating into microemulsion systems were consistent for all the non-ionic surfactants examined (Table 2). It was therefore apparent that, the microemulsion systems either protected the erythrocytes from the toxic effects of the surfactants or reduced their membrane interactions. Our findings also indicated as in Fig. 5 that, an increase in the proportion of oil significantly improved the modulating effects of the resultant microemulsions, thus providing a greater level of safety for possible parenteral administration.

However, microemulsions formulated with longer alkyl chain oils (e.g. ethyl oleate) had far greater modulation effects than those formulated with shorter alkyl chain oils (e.g. ethyl butyrate)

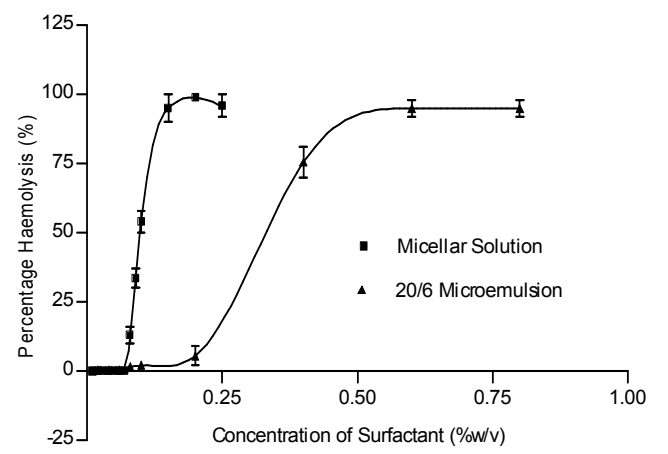

Fig. 4: The haemolytic effects of micelles of 1:2\%w/w Epicuron 200:C12N-O and its ethyl oleate/PBS microemulsions on human erythrocytes

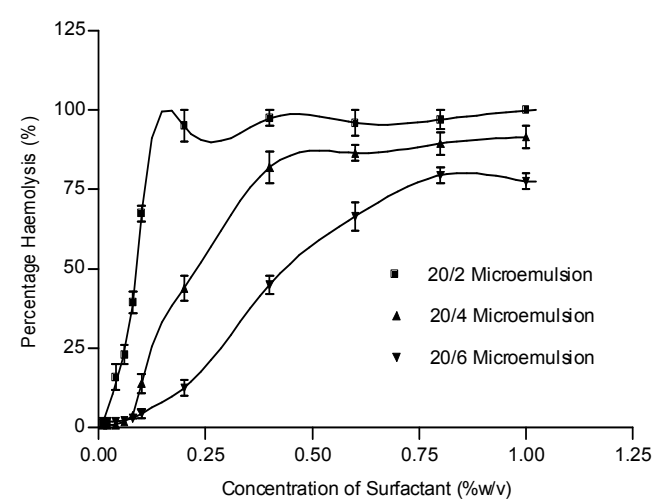

Fig. 5: The haemolytic effects of Brij 96 with different ratios of ethyl oleate/PBS microemulsions on human erythrocytes

(Figs. 6 and 7). Malcolmson (1992) demonstrated that, non-ionic surfactants formed more compacted interfaces with longer triglyceride 


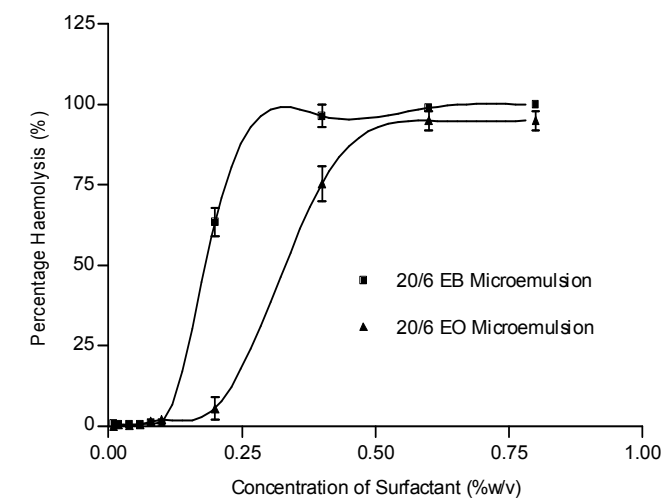

Fig. 6: The haemolytic effects of a $1: 2 \% \mathrm{w} / \mathrm{w}$ (Epicuron 200:C12N-O) microemulsions with the same ratio of different oils [ethyl butyrate (EB) and ethyl oleate (EO)] on human erythrocytes

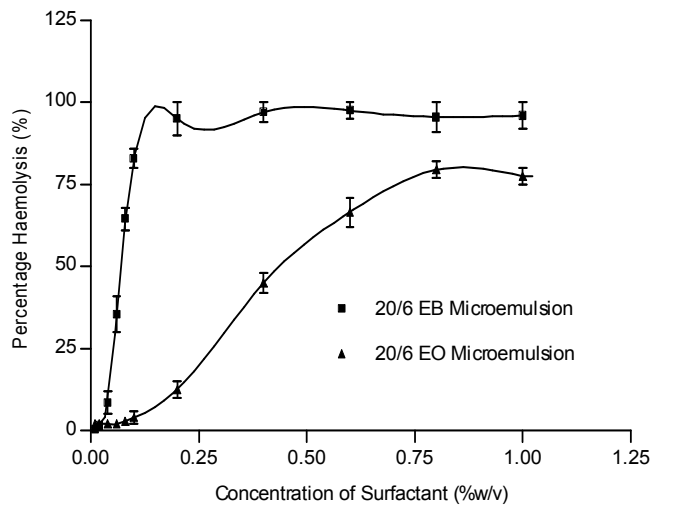

Fig. 7: The haemolytic effects of Brij 96 microemulsions with the same ratio of different oils [ethyl butyrate (EB) \& ethyl oleate (EO)] on human erythrocytes

Table 2: The haemolytic effects $\left(\mathrm{C}_{50}\right.$ values) of micellar solutions of non-ionic surfactants and their microemulsions with ethyl oleate and ethyl butyrate in PBS on human erythrocytes, indicating the percentage modulation of haemolytic activity by the microemulsions

\begin{tabular}{|c|c|c|c|c|c|c|}
\hline \multirow{2}{*}{$\begin{array}{l}\text { Surfactant/oil } \\
\text { ratio(w/w) }\end{array}$} & $\begin{array}{l}\text { Micellar } \\
\text { solutions } \\
\left(\mathrm{C}_{50}\right) \% \mathrm{w} / \mathrm{v}^{*}\end{array}$ & $\begin{array}{l}\text { Ethyl oleate } \\
\text { microemulsions } \\
\left(\mathrm{C}_{50}\right) \% \mathrm{w} / \mathrm{v}^{*}\end{array}$ & \multicolumn{2}{|l|}{$\begin{array}{l}\text { Percent } \\
\text { modulation } \\
(\%)\end{array}$} & $\begin{array}{l}\text { Ethyl butyrate } \\
\text { microemulsions } \\
\left(\mathrm{C}_{50}\right) \% \mathrm{w} / \mathrm{v}^{*}\end{array}$ & $\begin{array}{l}\text { Percent } \\
\text { modulation } \\
\qquad(\%)\end{array}$ \\
\hline & $4 \pm 0.001$ & & & & & \\
\hline & $25 / 2$ & 0.060 & \pm 0.003 & 36 & $0.058 \pm 0.002$ & 32 \\
\hline & $20 / 2$ & 0.086 & \pm 0.002 & 95 & $0.066 \pm 0.004$ & 50 \\
\hline & $20 / 4$ & 0.220 & \pm 0.010 & 400 & $0.054 \pm 0.003$ & 23 \\
\hline & $20 / 6$ & 0.420 & \pm 0.004 & 855 & $0.068 \pm 0.004$ & 55 \\
\hline & $15 / 2$ & 0.096 & \pm 0.002 & 118 & $0.052 \pm 0.001$ & 18 \\
\hline $\mathrm{C}_{12} \mathrm{E}_{10}$ & 0.05 & $2 \pm 0.003$ & & & & \\
\hline & $25 / 2$ & 0.056 & \pm 0.003 & 08 & $0.054 \pm 0.004$ & 04 \\
\hline & 20/1 & 0.058 & \pm 0.005 & 12 & 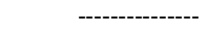 & --- \\
\hline & $20 / 2$ & 0.070 & \pm 0.001 & 35 & $0.056 \pm 0.002$ & 08 \\
\hline & $20 / 4$ & 0.110 & \pm 0.004 & 112 & --------------- & -- \\
\hline & $20 / 6$ & ------ & -------- & ---- & $0.063 \pm 0.003$ & 21 \\
\hline & $15 / 2$ & 0.062 & \pm 0.003 & 19 & -------------- & -- \\
\hline $\mathrm{C}_{12} \mathrm{~N}-\mathrm{O}$ & 0.06 & $4 \pm 0.001$ & & & & \\
\hline & $25 / 2$ & 0.064 & \pm 0.001 & 00 & $0.086 \pm 0.002$ & 34 \\
\hline & $20 / 2$ & 0.074 & \pm 0.003 & 16 & $0.090 \pm 0.006$ & 41 \\
\hline & $20 / 4$ & 0.110 & \pm 0.005 & 72 & --------------- & --- \\
\hline & $20 / 6$ & 0.160 & \pm 0.004 & 150 & $0.098 \pm 0.003$ & 53 \\
\hline & $15 / 2$ & 0.089 & \pm 0.002 & 39 & 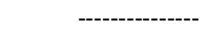 & -- \\
\hline \multicolumn{7}{|c|}{ EPIKURON 200: } \\
\hline \multicolumn{7}{|c|}{$\mathrm{C} 12 \mathrm{~N}-\mathrm{O}(1: 2 \mathrm{w} / \mathrm{w})$} \\
\hline & & 0.098 & \pm 0.002 & & & \\
\hline & $25 / 2$ & 0.160 & \pm 0.005 & 63 & $0.130 \pm 0.005$ & 33 \\
\hline & $20 / 1$ & 0.170 & \pm 0.004 & 74 & ------------ & -- \\
\hline & $20 / 2$ & 0.190 & \pm 0.001 & 94 & $0.150 \pm 0.006$ & 53 \\
\hline & $20 / 4$ & 0.260 & \pm 0.003 & 165 & ---------------- & --- \\
\hline & $20 / 6$ & 0.320 & \pm 0.005 & 227 & $0.185 \pm 0.003$ & 89 \\
\hline & $15 / 2$ & 0.175 & \pm 0.004 & 79 & ---------------- & --- \\
\hline
\end{tabular}

${ }^{*} C_{50}$ value $\pm S D$

50 Journal of Science and Technology, Volume 27 no. 2, August, 2007 
oils, thereby reducing the availability of free surfactant monomers for membrane effects. Moni et al (1992) also supported the hypothesis that the surfactant monomers are responsible for the disruption of plasma membrane integrity.

Our findings therefore, strongly support reports that, the modulation of the toxic biomembrane effects of non- ionic surfactants by microemulsion systems is due to a significant reduction of free surfactant monomers present in these systems (Atwood and Florence, 1983; Marriott et al., 1994) and greatly enhances their suitability for parenteral administration.

\section{CONCLUSION}

Generally, the areas of existence of the clear o/w microemulsions were dependent on the surfactant structure and the type of oil incorporated. The presence of electrolytes consisting mainly of monovalent ions had no effect on the formation, stability and area of existence of the microemulsions. The clear o/w microemulsion systems remained clear and stable even on dilution with water or PBS. Our results on the haemolytic effects of the micellar solutions of these non-ionic surfactants indicated that, the surfactant-cell membrane interactions (toxicity) were dependent on the nature and concentration of the surfactant, which agreed with the theory of intercalation of the hydrophobic portions of surfactant monomers with membrane lipid bilayers. The microemulsion systems significantly reduced the haemolytic effects of the surfactants on the human erythrocytes. The use of longer triglycerides and the highest possible oil/surfactant ratios greatly enhanced the modulation activity; thus offering a greater level of safety to the resultant microemulsions. These results lent good support and credence to the high potential safety and suitability of microemulsion systems as vehicles for improving parenteral drug administration.

\section{AKNOWLEDGEMENT}

We wish to thank DFID and the Association of Commonwealth Universities (ACU) for the fi- nancial support through a scholarship granted to MTB.

\section{REFERENCES}

Attwood, D. (1993). Microemulsions “In" Colloidal Drug Delivery Systems, Marcel Dekker Inc. New York, Basel, Hong Kong pp. 31-70.

Atwood, D. and Florence, A. T. (1983). Biological implications of surfactant presence in formulations. "In" Surfactant Systems, Chapman and Hall, 388-467.

Aveyard, R., Binks, B. P. and Lawless, T. A. (1981). Electrolyte effects on non-ionic surfactant systems. J. Chem, Soc. Faraday Trans. 81: 2169-2171.

Bhargava, H. N., Narurkar, A. and Lieb, L. M. (1987). Using microemulsions for drug delivery. Pham. Technol. 11: 46-54.

Coleman, R. and Holdsworth, G. (1975). Effects of detergents on erythrocytes membranes: different patterns of solubilisation of the membrane proteins by micelles on the intestinal absorption of streptomycin in rat. Int. J. Pharm. 4: 271-279.

Coleman, R. Lowe, P.J. and Billington, D. (1980). Membrane lipid composition and susceptibility to bile salt damage. Biochim. Biophys. Acta. 599: 294-300.

Fubini, B., Gasco, M. R. and Gallarate, M. (1989). Microcalorimetric study of microemulsions as potential drug delivery systems II. Evaluation of enthalpy in the presence of drugs. Int. J. Pharm. 50: 213-2 17.

Holtzschere, C. and Candau, F. (1988). The effects of $\mathrm{pH}$ changes on the stability of colloids containing surface active agents. $J$. Colloid Interface Sci. 125(1): 97-110.

Isomaa, B., Engblom, A. C. and Hagerstrand, H. (1988). The time-dependence of amphiphileinduced haemolysis. Toxicology, 48: 285291. 
Langevin, D. (1991). The influence of dilution of non-ionic surfactant micellar solutions and microemulsions with buffers containing monovalent, divalent and trivalent ions. Adv. Colloid Interphace Sci. 34 : 583.

Lawrence, M. J. and Devinsky, F. (1988). The formulation of stable microemulsions with non-ionic surfactants. J. Pharm. Pharmacol. (Supp : 124 P): 92-98.

Malcolmson, C. A. (1992). The physiological properties of non-ionic oil-in-water microemulsions. Ph. D. Thesis, Chelsea Dept. of Pharmacy, King's College, London. pp 4767. "Unpublished"

Malcolmson, C. and Lawrence, M. J. (1993). A comparison of the incorporation of testosterone, testosterone propionate and testosterone enanthate in non-ionic micellar and microemulsion systems. J. Pharm. Pharmacol. 44: 142.

Marriott, C., Sajadi-Tabassi, S. A. and Martin, G. P. (1994). Haemolytic effects of non-ionic surfactants. British Pharmaceutical Conference, (September): 47- 48.
Martin, G. P., El-Hariri, M. L. and Marriott, C. (1992). Bile salts and Lysophosphatidylcholine-induced membrane damage in human erythrocytes. J. Pharm. Pharmacol. 44: 646650.

Moni, R. W., Parsons, P. G., Quin, R. J and Willis, R. J. (1992). The activity of surfactant micellar solutions on plasma membranes. Biochem. Biophys. Res. Comm. 182 (1): 115-120.

Osborne, D. W., Ward, A. J. I. and O’Neil, K. J. (1991). Microemulsions as topical delivery vehicles: In vitro transdermal studies of a model hydrophilic drug. Pharm, Pharmacol. 43: 451 .

Ziv, E., Eldor, A., Kleinman, Y., Bar-on, H. and Kidron, M. (1983). Bile salts facilitate the absorption of heparin from the intestines. Biochem, Pharmacol, 32: 773 -776.

52 Journal of Science and Technology, Volume 27 no. 2, August, 2007 